\title{
Regionalização dos serviços de saúde - municípios polo: revisão bibliográfica de 2000-2010
}

\author{
Suzinara Beatriz Soares de Lima*, Pâmela Ferreira Todendi**, \\ Fernanda Sarturi*, Neida Luiza Kaspary Pellenz*
}

\begin{abstract}
Resumo: Com a criação do Sistema Único de Saúde (SUS), buscam-se estratégias de regionalização e hierarquização da assistência à saúde da população brasileira. 0 objetivo deste estudo é identificar as publicações sobre a regionalização dos serviços de saúde por meio de municípios-pólo. 0 estudo é exploratório de caráter bibliográfico, sendo as fontes de investigação artigos científicos publicados em periódicos da área da saúde no Scientific Eletronic Library Online (SCIELO) e na Literatura Latino-Americana e do Caribe em Ciências da Saúde (LILACS). Na a coleta dos dados foram utilizadas as seguintes palavras-chave: "regionalização em saúde", "municípios-pólo em saúde", "consórcios regionais de saúde", "referência e contra-referência em saúde", com recorte temporal de 2000 a 2010. Os resultados obtidos revelam a escassa publicação no que se refere a estudos de regionalização dos serviços de saúde em municípios pólo, pois em 10 anos verificou-se a produção total de 10 artigos.
\end{abstract}

Descritores: Serviços de saúde, Gestão em saúde, Regionalização.

\section{Regionalization of health services - municipalities pole: review of literature}

2000-2010

\begin{abstract}
With the creation of the Unified Health System (SUS), are sought regionalization strategies and prioritization of health care to the population. The objective of this study is to identify publications on the regionalization of health services by municipalities pole. The study is exploratory, literature, and sources of research articles published in scientific journals in the area of health in the Scientific Electronic Library Online (SciELO) and the Latin American and Caribbean Health Sciences (LILACS). In collecting the data we used the following keywords: "regionalization in health", "municipal healthpole", "regional consortia of health", "reference and counter-reference health" with the time frame of 2000 2010. The results show the scarce publication with regard to studies of regionalization of health services in municipalities pole, because in 10 years there has been a total production of 10 articles.
\end{abstract}

Descriptors: Health, Health managemenT, Regionalization.

*Enfermeira pela Universidade Federal de Santa Maria (UFSM), Santa Maria, Rio Grande do Sul.

**Farmacêutica pela Universidade Federal de Santa Maria (UFSM), Santa Maria, Rio Grande do Sul. 


\section{Introdução}

Os serviços de saúde devem ser organizados em níveis de complexidade tecnológica crescente, dispostos em área geográfica delimitada e com definição da população a ser atendida. Isto implica na capacidade destes serviços em oferecer a uma determinada população todas as modalidades de assistência, bem como 0 acesso a todos os níveis de atendimento possibilitando um ótimo grau de resolubilidade; assim um dos objetivos da Lei Federal do Brasil 8.080 que é prestar assistência às pessoas por intermédio de ações de promoção, proteção e recuperação da saúde, com a realização integrada das ações assistenciais e das atividades preventivas. ${ }^{1} 0$ acesso da população a rede de serviços a saúde deve se dar por meio dos serviços de nível primário de atenção, que necessitam estar qualificados para atender e resolver os principais problemas da população, estes resolvidos a nível municipal. Os problemas de saúde mais complicados devem ser referenciados para os serviços de maior complexidade tecnológica.

Uma rede de serviços, organizada de forma hierarquizada e regionalizada, permite conhecimento e resolutividade dos problemas de saúde da população da área delimitada. Assim favorece-se ações de vigilância epidemiológica, sanitária, controle de vetores, educação em saúde, além das ações de atenção ambulatorial e hospitalar em todos os níveis de complexidade. ${ }^{1}$ Ou seja, desvelar a capacidade de resolução dos serviços em todos os níveis de assistência possibilita traçar estratégias e perceber os principais estudos na área, bem como as necessidades e possibilidades de realizar redes de atendimento à população.

De acordo com a Lei 8.080 de 1990, uma das principais diretrizes do Sistema Único de Saúde (SUS) é a regionalização e hierarquização da rede de serviços de saúde. A partir desta Lei, em 2002 foi criado a Norma Operacional de Atenção à Saúde (NOAS-SUS), que tem como estratégia a regionalização das ações em saúde a partir do Plano Diretor de Regionalização (PDR). Este, divide os Estados em regiões/microrregiões e módulos assistenciais, com definição de municípios-pólo e municípios-sede e fluxos de referência e contra referências intermunicipais, de acordo com a capacidade instalada e as necessidades da população. ${ }^{2}$ A regionalização do SUS ainda enfrenta importantes desafios, em particular a implantação do PDR, formando assim municípios-pólo de atenção. Com a regionalização dos serviços mais complexos, seria indiscutivelmente melhor a acessibilidade para os cidadãos, bem como para os grandes centros pela diminuição da demanda diária provenientes de todos os cantos do Estado.

A Lei 8.080 instituiu o SUS, com comando único em cada esfera de governo e definiu o Ministério da Saúde como gestor no âmbito da União. A Lei, no seu Capítulo II - Dos Princípios e Diretrizes, Art. $7^{\circ}$, estabelece entre os princípios do SUS a "universalidade de acesso aos serviços de saúde em todos os níveis de assistência". Isso se constituiu em uma grande alteração da situação até então vigente. O Brasil passa a contar com um sistema público de saúde único e universal. ${ }^{3}$

A Lei 8.142, de 28 de dezembro de 1990, dispõe sobre a participação da comunidade

Saúde (Santa Maria), v.38, n.2, p. 95-106, 2012. Regionalização dos serviços de saúde - municipios polo: revisão bibliográfica de 2000-2010 na gestão do Sistema Único de Saúde (SUS) e sobre as transferências intergovernamentais de recursos financeiros na área de saúde. ${ }^{1}$ Com efeito, a primeira década do SUS foi marcada por um processo de intensa transferência de competências e recursos em direção aos municípios, orientado pelos instrumentos normativos emanados do Ministério da Saúde: 
as Normas Operacionais Básicas (NOBs). Mediante a definição de critérios de habilitação e de incentivos operados pelo financiamento, as sucessivas NOBs conduziram os municípios à assunção progressiva da gestão de ações e serviços de saúde em seus territórios. ${ }^{4}$

O movimento descentralizador foi iniciado com a implementação das Normas Operacionais Básicas de 1993 (NOB 01/93) e especialmente a de 1996 (NOB 01/96), que induziram a redefinição de funções e competências das três esferas de governo (federal, estadual e municipal) no que se refere à gestão, organização e prestação de serviços de saúde, através da transferência de recursos (financeiros, basicamente, mas também físicos, humanos e materiais) do nível federal e estadual para os municípios. Nesse contexto, um processo de (re)centralização estaria se iniciando no momento atual, com a implementação da Norma Operacional da Assistência à Saúde 2001 (NOAS), que pretendia estimular um fortalecimento do papel das Secretarias Estaduais de Saúde, no sentido de assumirem a coordenação de um processo de regionalização da assistência que implica na organização de sistemas microrregionais de saúde, com os quais se busca superar uma "excessiva" descentralização da gestão ocorrida no momento anterior. ${ }^{5}$

A NOAS 2001 enfatiza a cooperação e recupera a noção de economia de escala como fundamento para a racionalização (e a reconcentração) de recursos, especialmente aqueles destinados aos investimentos em serviços de média e alta complexidade, realizados nos municípios "pólos" de microrregiões de saúde. Finalmente, do ponto de vista técnicoassistencial, a NOAS resgata a possibilidade de se construir sistemas de serviços de saúde que, ultrapassando os limites territoriais dos municípios (levando em conta que a maioria é de pequeno porte), alcancem a integralidade do cuidado (integralidade relativa à capacidade instalada em cada microrregião). Para isso, assume uma lógica organizacional e programática cujo elemento de referência é o grau de complexidade tecnológica dos serviços existentes nos diversos municípios, propondo uma delimitação territorial correspondente ao estabelecimento de dois níveis de atenção: a atenção básica ampliada, organizada no espaço de um módulo assistencial e a atenção integral à saúde, que constitui o conjunto de módulos assistenciais integrados em uma microrregião de saúde. ${ }^{5}$

$\mathrm{Na}$ NOAS, a regionalização foi enfatizada como estratégia necessária para que 0 processo de descentralização se aprofundasse. A esfera estadual passa a ordenar 0 processo de regionalização sanitária com o Plano Diretor de Regionalização (PDR), instrumento que traduziria o planejamento regional de acordo com as particularidades de cada estado (e do Distrito Federal), em consonância com os recursos disponíveis. Estes seriam alocados conforme a Programação Pactuada e Integrada, e com previsões de necessidades de novos recursos expressas no Plano Diretor de Investimento. A partir desse planejamento regional, pretendia-se garantir acesso aos serviços de saúde em qualquer nível de atenção a todos os cidadãos, fundamentando-se na configuração de sistemas funcionais e resolutivos, na organização de redes hierarquizadas de serviços e no estabelecimento de mecanismos e fluxos de referência e contra-referência intermunicipais. ${ }^{4}$

No sistema de saúde regionalizado, a disponibilidade de equipamentos sociais mais próximos aos usuários, amplia a racionalidade dos serviços de saúde de maior densidade tecnológica como a assistência hospitalar. Dessa forma, considerando a complexidade das tecnologias utilizadas e a necessidade de recursos humanos especializados, as unidades hospitalares estarão organizadas para prestar assistência às principais causas de morbimortalidade. Direciona-se ainda, os fundos de saúde municipais, estaduais e federais

Saúde (Santa Maria), v.38, n.2, p. 95-106, 2012 Lima, S. B. S.; Todendi, P. F.; Sarturi, F.; Pellenz, N. L.

ISSN 2236-5843 
no sentido das necessidades de saúde da população adscrita, uma vez que esse nível assistencial representa importante parcela orçamentária do SUS. Configurada a oferta organizada, 0 arranjo de unidades de referência regional, subsidiará 0 acesso aos hospitais especializados para a população de pequenos municípios, conforme garantido constitucionalmente e normatizado na Norma Operacional de Assistência à Saúde. ${ }^{6}$

Em 2006, com o lançamento do Pacto pela Saúde, novas diretrizes são preconizadas para a regionalização do sistema de saúde, baseadas em um fortalecimento da pactuação política entre os entes federados, sobretudo no âmbito municipal, e na diversidade econômica, cultural e social das regiões do país para a redefinição das regiões de saúde. ${ }^{7}$

Os principais instrumentos de planejamento da regionalização criados foram o PDR, 0 plano diretor de investimento - PDI e a programação pactuada e integrada da atenção em saúde - PPI. Cada Comissão Intergestora Bipartite (CIB) deverá estabelecer qual o desenho mais apropriado para garantir 0 acesso com qualidade às ações e serviços de saúde. Portanto, a definição do conjunto de ações e serviços a serem desempenhadas em cada região deverá estar de acordo com as necessidades de saúde e da capacidade de oferta da região. As regiões de saúde são recortes territoriais inseridos em um espaço geográfico contínuo, identificadas pelos gestores municipais e estaduais a partir de identidades culturais, econômicas e sociais, de redes de comunicação e infraestrutura de transportes compartilhados do território. Para a constituição de uma rede de atenção à saúde regionalizada em uma determinada região, é necessário a pactuação entre os gestores envolvidos para garantir a atenção na alta complexidade e em parte da média. Estas regiões devem pactuar entre si arranjos inter-regionais, com agregação de mais de uma região em uma macrorregião; o ponto de corte da média complexidade que deve estar na região ou na macrorregião deve ser pactuado na CIB, a partir da realidade de cada estado. ${ }^{8}$

Como questão norteadora, tem-se: Como está a regionalização dos serviços de saúde nos municípios-pólo? Este trabalho tem como acontece a regionalização dos serviços de saúde por meio de municípios-pólo, bem como os municípios-pólo melhoram a qualidade e acessibilidade da população a saúde e verificar se há organização dos sistemas microrregionais de saúde.

Saúde (Santa Maria), v.38, n.2, p. 95-106, 2012. Regionalização dos serviços de saúde - municípios polo: revisão bibliográfica de 2000-2010

\section{Metodologia}

Este estudo é exploratório, de natureza descritivo/qualitativo de caráter bibliográfico. As fontes de investigação foram artigos científicos publicados em periódicos da área da saúde no Scientific Eletronic Library Online (SCIELO) e na Literatura Latino-Americana e do Caribe em Ciências da Saúde (LILACS).

Para a coleta dos dados foram utilizadas as seguintes palavras-chave na busca: "regionalização em saúde", "municípios-pólo em saúde", "consórcios regionais de saúde", "referência e contra-referência em saúde". Os critérios de inclusão/ exclusão foram feitos por meio da literatura, com recorte temporal de 2000 a 2010. Os periódicos estrangeiros foram excluídos do trabalho, bem como os que não estavam disponíveis na integra. A busca foi realizada na biblioteca virtual do SCIELO, LILACS no mês de abril e maio de 2011.

Foi construído um instrumento contendo os seguintes dados: local e ano, autor, título, fonte/biblioteca virtual, objetivos e observação a fim de facilitar 0 estudo. 0 tratamento dos 
resultados analisados foi feito por categorização dos dados obtidos e após a discussão dos resultados com as referências da literatura. Seguiu-se a análise dos dados por conteúdo. ${ }^{9}$ As categorias que emergiram foram: municípios pólo em saúde; consórcios regionais em saúde; referencia e contra referência em saúde e; regionalização em saúde. As categorias foram divididas e encontram-se nos quadros apresentados a seguir.

\section{Resultados e discussão}

Com a palavra "município pólo em saúde" no LILACS foram achados dez artigos e no SCIELO seis artigos no dia 09/05/2011. Destes, foram selecionados apenas dois artigos, pois dois eram estrangeiros no LILACS e um no SCIELO, e os demais não falavam sobre a temática. Apenas dois artigos foram selecionados no LILACS que abordavam o assunto em questão, no SCIELO um artigo foi selecionado, mas este também foi encontrado no LILACS. Abaixo segue 0 Quadro 1 que demonstra os resultados desta etapa da pesquisa.

\begin{tabular}{|c|c|c|c|c|c|}
\hline Local e ano & Autor & Título & $\begin{array}{c}\text { Fontel } \\
\text { Biblioteca } \\
\text { Virtual }\end{array}$ & Objetivos & OBS.: \\
\hline $\mathrm{RJ}-2005$ & $\begin{array}{l}\text { Elisabeth Costa } \\
\text { Dias; Maria da } \\
\text { Graça Hoefel }\end{array}$ & $\begin{array}{c}\text { O desafio de } \\
\text { implementar as } \\
\text { ações de saúde } \\
\text { do trabalhador no } \\
\text { SUS: a estratégia } \\
\text { do RENAST }\end{array}$ & $\begin{array}{l}\text { Ciência \& } \\
\text { Saúde Coletiva; } \\
\text { LILACS e } \\
\text { SCIELO }\end{array}$ & $\begin{array}{l}\text { O CRST deixa } \\
\text { de ser porta de } \\
\text { entrada e } \\
\text { assume o papel } \\
\text { de suporte } \\
\text { técnico, pólo } \\
\text { irradiador no } \\
\text { território de } \\
\text { abrangência. }\end{array}$ & $\begin{array}{l}\text { CRST - Centros } \\
\text { de Referência em } \\
\text { Saúde do } \\
\text { Trabalhador. } \\
\text { RENAST- Rede } \\
\text { de Atenção } \\
\text { Integral à Saúde } \\
\text { do Trabalhador }\end{array}$ \\
\hline$M G-2010$ & $\begin{array}{c}\text { Auta, S. Step } \\
\text { han; Ivan, C. F. } \\
\text { Chebli; Elisabeth, } \\
\text { J. M. Jacometti; } \\
\text { Marcélia, G. } \\
\text { Paiva }\end{array}$ & $\begin{array}{l}\text { Regionalização } \\
\text { sob a ótica dos } \\
\text { gestores: uma } \\
\text { abordagem } \\
\text { dialética }\end{array}$ & $\begin{array}{l}\text { Rev. APS, Juiz } \\
\text { de Fora; LILACS }\end{array}$ & $\begin{array}{c}\text { Identificar } \\
\text { como se } \\
\text { estabelece as } \\
\text { relações entre } \\
\text { os gestores dos } \\
\text { municípios } \\
\text { limítrofes com o } \\
\text { município Juiz } \\
\text { de Fora, pólo } \\
\text { macrorregional } \\
\text { de atenção à } \\
\text { saúde. }\end{array}$ & $\begin{array}{c}\text { Definiu-se que } \\
\text { há necessidade } \\
\text { de um } \\
\text { planejamento da } \\
\text { gestão do SUS } \\
\text { (PDR e PPI) que } \\
\text { considere a } \\
\text { demanda em } \\
\text { saúde e que } \\
\text { contemple as } \\
\text { múltiplas } \\
\text { demandas }\end{array}$ \\
\hline
\end{tabular}

Quadro 1-Resultados da busca dos Municípios pólo em saúde. Revisão Bibliográfica de 2000-2010: municípios pólo em saúde, 2011.

A busca com a palavra "consórcios regionais em saúde" realizada no dia 11/05/2011, no LILACS apresentou quatro artigos relacionados com o assunto, deles apenas um possuía seu texto na íntegra, que se encontra no Quadro 2. Os demais artigos apresentaram somente os resumos, em geral eles defendem a importância dos consórcios em saúde, pois ampliam o espectro da oferta de serviços a sua população e as relações intergovernamentais

Saúde (Santa Maria), v.38, n.2, p. 95-106, 2012. Lima, S. B. S.; Todendi, P. F.; Sarturi, F.; Pellenz, N. L. K. ISSN 2236-5843 99 cooperativas. No SCIELO não foram encontrado artigos para este assunto. 


\begin{tabular}{|c|c|c|c|c|c|}
\hline Local e ano & Autor & Título & $\begin{array}{c}\text { Fontel } \\
\text { Biblioteca } \\
\text { Virtual }\end{array}$ & Objetivos & OBS.: \\
\hline$\overline{R J}-200 \overline{6}$ & $\begin{array}{c}\text { Luiz Äntonio } \\
\text { Neves; José } \\
\text { Mendes Ribeiro }\end{array}$ & $\begin{array}{l}\text { Consórcios de } \\
\text { saúde: estudo de } \\
\text { caso exitoso }\end{array}$ & $\begin{array}{l}\text { Cadernos de } \\
\text { Saúde Pública; } \\
\text { LILACS }\end{array}$ & $\begin{array}{l}\text { Efetuar um } \\
\text { estudo de caso } \\
\text { sobre os } \\
\text { consórcios } \\
\text { intermunicipais } \\
\text { de saúde mais } \\
\text { antigo do setor } \\
\text { da saúde, e } \\
\text { elaborar um } \\
\text { conjunto de } \\
\text { recomendações }\end{array}$ & $\begin{array}{l}\text { Verificou-se que } \\
\text { os consórcios } \\
\text { intermunicipais } \\
\text { mantém um forte } \\
\text { vínculo com a } \\
\text { estratégia de } \\
\text { regionalização da } \\
\text { saúde no Brasil }\end{array}$ \\
\hline
\end{tabular}

Quadro 2 - Resultados da busca de consórcios regionais em saúde: Revisão Bibliográfica de 2000-2010: municípios pólo em saúde, 2011.

A busca pelas palavras "referência e contra-referência em saúde" foi realizada no dia 11/05/2011 no LILACS e foram identificados 59 artigos em português, os estrangeiros foram 18 artigos, que foram excluídos do estudo. No SCIELO foram encontrados 48 artigos em português e excluíram-se os estrangeiros, que foram 11 artigos. Refinando a pesquisa para referência e contra-referência em saúde regional, no LILACS foram encontrados dois artigos, sendo que ambos não contemplam o assunto abordado neste trabalho. No site SCIELO também foram identificados dois artigos, o primeiro está descrito no Quadro 3 e o segundo descartado, pois, é anterior ao ano 2000.

\begin{tabular}{|c|c|c|c|c|c|}
\hline Local e ano & Autor & Título & $\begin{array}{c}\text { Fontel } \\
\text { Biblioteca } \\
\text { Virtual }\end{array}$ & Objetivos & OBS.: \\
\hline$S P-2002$ & $\begin{array}{c}\text { Giselle L. } \\
\text { Monnerat; Mônica } \\
\text { de Castro Maia } \\
\text { Senna; Rosimary } \\
\text { G. de Souza }\end{array}$ & $\begin{array}{l}\text { A reorganização } \\
\text { dos serviços de } \\
\text { saúde no cenário } \\
\text { local }\end{array}$ & $\begin{array}{l}\text { Ciência e Saúde } \\
\text { Coletiva; SCIELO }\end{array}$ & $\begin{array}{c}\text { Tomamos o } \\
\text { município de São } \\
\text { Gonçalo, como } \\
\text { lócus de análise, } \\
\text { buscando } \\
\text { dimensionar o } \\
\text { impacto da } \\
\text { descentralização } \\
\text { na reorganização } \\
\text { da rede de } \\
\text { serviços, a partir } \\
\text { da composição } \\
\text { dos serviços em } \\
\text { termos da } \\
\text { quantidade e } \\
\text { qualidade da } \\
\text { oferta de } \\
\text { cuidados. }\end{array}$ & $\begin{array}{l}\text { O poder político } \\
\text { no município se } \\
\text { conforma de uma } \\
\text { maneira ineficaz e } \\
\text { que esbarra em } \\
\text { constrangimentos. }\end{array}$ \\
\hline
\end{tabular}

Saúde (Santa Maria), v.38, n.2, p. 95-106, 2012 Regionalização dos serviços de saúde - municípios polo: revisão bibliográfica de 2000-2010

Quadro 3 - Resultados da busca de Referência e contra-referência em saúde: Revisão Bibliográfica de 2000-2010: municípios pólo em saúde, 2011. 
Na busca realizada no dia 18/05/2011 no SCIELO com as palavras "regionalização em saúde", foram achados 42 artigos relacionados com o tema, destes todos eram nacionais; seis foram excluídos por estarem abaixo do ano 2000, restando assim 36 artigos. No site LILACS foram identificados 385 artigos, destes foram excluídos 87 por serem estrangeiros, 147 por serem do ano inferior a 2000. Dos 299 artigos encontrados no LILACS, (a partir do idioma português), quando selecionado o período de publicação de 2000 a 2010, ficaram 151 artigos, destes, apenas 91 encontravam-se disponiveis na íntegra.

$\mathrm{Na}$ tentativa de refinar o estudo, foi optado por ler todos os artigos, a fim de verificar os mais relevantes ao assunto; dentre eles, foram selecionados quatro no site SCIELO e três no site LILACS, apenas um artigo dentre os selecionados estava presente em ambos os sites. Os artigos selecionados seguem no Quadro 4.

\begin{tabular}{|c|c|c|c|c|c|}
\hline Local e ano & Autor & Título & $\begin{array}{c}\text { Fontel } \\
\text { Biblioteca } \\
\text { Virtual }\end{array}$ & Objetivos & OBS.: \\
\hline RJ, 2002 & $\begin{array}{l}\text { Carmen Fontes } \\
\text { Teixeira }\end{array}$ & $\begin{array}{l}\text { Promoção e } \\
\text { vigilância da } \\
\text { saúde no } \\
\text { contexto da } \\
\text { regionalização da } \\
\text { assistência à } \\
\text { saúde no SUS. }\end{array}$ & $\begin{array}{l}\text { Cadernos de } \\
\text { Saúde Pública; } \\
\text { SCIELO e } \\
\text { LILACS }\end{array}$ & $\begin{array}{c}\text { Avançar na } \\
\text { construção de } \\
\text { sistemas } \\
\text { microrregionais } \\
\text { que garantam a } \\
\text { integralidade da } \\
\text { atenção à saúde } \\
\text { em cada região e } \\
\text { Estado do país. }\end{array}$ & $\begin{array}{c}\text { Reorientação da } \\
\text { assistência } \\
\text { individual e } \\
\text { coletiva, na } \\
\text { medida em que } \\
\text { venham a ser } \\
\text { incorporadas ao } \\
\text { processo de } \\
\text { implementação } \\
\text { da NOAS. }\end{array}$ \\
\hline SP; 2009 & $\begin{array}{l}\text { Emerson Assis, } \\
\text { et al. }\end{array}$ & $\begin{array}{l}\text { Regionalização } \\
\text { e novos rumos } \\
\text { para o SUS: } \\
\text { experiência de } \\
\text { um colegiado } \\
\text { regional }\end{array}$ & $\begin{array}{l}\text { Saúde e } \\
\text { Sociedade; } \\
\text { SCIELO }\end{array}$ & $\begin{array}{l}\text { Este trabalho } \\
\text { apresenta a } \\
\text { experiência } \\
\text { positiva de } \\
\text { implantação de } \\
\text { um Colegiado } \\
\text { Regional no } \\
\text { Estado de São } \\
\text { Paulo. }\end{array}$ & $\begin{array}{c}\text { Com a } \\
\text { implementação } \\
\text { do Pacto pela } \\
\text { Saúde, na sua } \\
\text { dimensão da } \\
\text { gestão, iniciou } \\
\text { esse processo, } \\
\text { que tem se } \\
\text { mostrado } \\
\text { promissor para o } \\
\text { desenvolvimento } \\
\text { e crescimento do }\end{array}$ \\
\hline $\begin{array}{l}\text { São Carlos; } \\
2008\end{array}$ & $\begin{array}{c}\text { Cassius T. } \\
\text { Scarpin; et al }\end{array}$ & $\begin{array}{c}\text { Otimização no } \\
\text { serviço de saúde } \\
\text { no estado do } \\
\text { Paraná: fluxo de } \\
\text { pacientes e novas } \\
\text { configurações } \\
\text { hierárquicas }\end{array}$ & $\begin{array}{l}\text { Gestão e } \\
\text { Produção; } \\
\text { SCIELO }\end{array}$ & $\begin{array}{c}\text { Otimizar o } \\
\text { serviço de saúde } \\
\text { com relação ao } \\
\text { fluxo de pacientes } \\
\text { dentro do estado } \\
\text { e a regionalização } \\
\text { (divisão) do } \\
\text { estado. }\end{array}$ & $\begin{array}{l}\text { SUS nacional } \\
\text { Quanto a } \\
\text { regionalização } \\
\text { consiste em } \\
\text { dividir o estado } \\
\text { em regiões } \\
\text { menores, } \\
\text { formadas por } \\
\text { várias cidades, } \\
\text { vinculadas a uma } \\
\text { cidade sede, } \\
\text { principal }\end{array}$ \\
\hline
\end{tabular}

Saúde (Santa Maria), v.38, n.2. p. 95-106, 2012 Lima, S. B. S.; Todendi, P. F.; Sarturi, F.; Pellenz, N. L. K. 
Continuação Quadro 4.

\begin{tabular}{|c|c|c|c|c|c|}
\hline S.P.; 2009 & $\begin{array}{l}\text { José Angelo } \\
\text { Machado }\end{array}$ & $\begin{array}{l}\text { Pacto de gestão } \\
\text { na saúde: até } \\
\text { onde esperar uma } \\
\text { "regionaliza-ção } \\
\text { solidária e } \\
\text { cooperativa"? }\end{array}$ & $\begin{array}{c}\text { Revista } \\
\text { Brasileira de } \\
\text { Ciências Sociais; } \\
\text { SCIELO }\end{array}$ & $\begin{array}{c}\text { Articular } \\
\text { municípios } \\
\text { "exportadores" e } \\
\text { "importadores" de } \\
\text { serviços de saúde } \\
\text { com maior } \\
\text { complexidade } \\
\text { tecnológica sob a } \\
\text { coordenação dos } \\
\text { governos } \\
\text { estaduais }\end{array}$ & $\begin{array}{l}\text { responsável pelo } \\
\text { atendimento. } \\
\text { O Pacto de } \\
\text { Gestão do SUS, } \\
\text { firmado entre as } \\
\text { três esferas de } \\
\text { governo no ano } \\
\text { de } 2006 \text { e } \\
\text { atualmente em } \\
\text { desenvolvimento, } \\
\text { venha a } \\
\text { consumar a } \\
\text { almejada } \\
\text { regionalização } \\
\text { solidária e } \\
\text { cooperativa. }\end{array}$ \\
\hline $\begin{array}{l}\text { Porto Alegre; } \\
2010\end{array}$ & $\begin{array}{r}\text { Maristela Correa } \\
\text { Rodrigues de lima }\end{array}$ & $\begin{array}{l}\text { Fluxos de } \\
\text { utilização de } \\
\text { serviços } \\
\text { hospitalares no } \\
\text { processo de } \\
\text { regionalização em } \\
\text { municípios da } \\
\text { metade sul do } \\
\text { RS. }\end{array}$ & $\begin{array}{l}\text { www.bibliotecadi } \\
\text { gital.ufrgs.br; } \\
\text { LILACS }\end{array}$ & $\begin{array}{l}\text { Analisar, sob à } \\
\text { perspectiva da } \\
\text { regionalização, os } \\
\text { fluxos de serviços } \\
\text { hospitalares em } \\
\text { municípios da } \\
\text { Metade Sul do } \\
\text { Rio Grande do } \\
\text { Sul, por meio do } \\
\text { perfil das } \\
\text { internações e } \\
\text { mobilidade de } \\
\text { usuários no } \\
\text { período } 2000 \text { a } \\
2006 .\end{array}$ & $\begin{array}{c}\text { Na assistência } \\
\text { hospitalar, dada a } \\
\text { complexidade dos } \\
\text { serviços e o } \\
\text { pequeno porte da } \\
\text { maioria dos } \\
\text { municípios } \\
\text { brasileiros que } \\
\text { não dispõem de } \\
\text { condições para } \\
\text { ofertar todos os } \\
\text { níveis de } \\
\text { complexidade em } \\
\text { seu território, a } \\
\text { regionalização } \\
\text { assume } \\
\text { relevância na } \\
\text { organização } \\
\text { dessa rede. }\end{array}$ \\
\hline
\end{tabular}




\begin{tabular}{|c|c|c|c|c|c|}
\hline Brasília; 2004 & $\begin{array}{l}\text { Brasil. Conselho } \\
\text { Nacional de } \\
\text { Secretários de } \\
\text { Saúde }\end{array}$ & $\begin{array}{l}\text { Convergências e } \\
\text { divergências } \\
\text { sobre a gestão e } \\
\text { regionalização do } \\
\text { SUS }\end{array}$ & $\begin{array}{l}\text { Brasília; } \\
\text { CONASS; } \\
\text { LILACS }\end{array}$ & $\begin{array}{c}\text { Objetivo de } \\
\text { aprofundar o } \\
\text { debate sobre a } \\
\text { Gestão e a } \\
\text { Regionalização } \\
\text { do SUS, visando } \\
\text { levantar subsídios } \\
\text { do CONASS para } \\
\text { a construção do } \\
\text { processo } \\
\text { normativo do } \\
\text { SUS. }\end{array}$ & $\begin{array}{l}\text { Em março de } \\
2004 \text { foi } \\
\text { realizada, em } \\
\text { Natal - RN, a } \\
\text { Assembléia dos } \\
\text { Secretários } \\
\text { Estaduais de } \\
\text { Saúde em } \\
\text { continuidade ao } \\
\text { processo de } \\
\text { discussão e } \\
\text { elaboração de } \\
\text { propostas do } \\
\text { CONASS sobre } \\
\text { Gestão e } \\
\text { regionalizacao / } \\
\text { Descentralização } \\
\text { do SUS. }\end{array}$ \\
\hline
\end{tabular}

Quadro 4 - Resultados da busca Regionalização em saúde: Revisão Bibliográfica de 2000-2010: municípios pólo em saúde, 2011.

As publicações mais encontradas se referem a: regionalização dos serviços de saúde no SUS, sua implantação e as melhorias à saúde da população quando há a regionalização dos serviços de saúde. Também se apresentam discussões sobre os Consórcios Regionais de Saúde como subsídios para melhorar a regionalização dos serviços do SUS, e discussões em efetivar de fato a Norma Operacional da Assistência à Saúde (NOAS) implementando o planejamento de regionalização (PDR e PDI) juntamente com o Pacto de Gestão do SUS.

Nos últimos cinco anos, observa-se um aumento de publicações enfocando a regionalização dos serviços de saúde no SUS. As regiões do Brasil, que mais discutiram 0 assunto encontram-se no Sudeste conforme as tabelas 1, 2, 3 e 4.

Há o enfoque que de o processo de regionalização da saúde o primeiro ator implicado neste processo é o gestor municipal, e uma das medidas a serem tomadas é a adoção de políticas públicas que incidam no modelo de atenção desenvolvido pelo município. ${ }^{10}$ Os prestadores hospitalares também são importantes aliados. Ao seu engajamento, está relacionado 0 aumento na resolutividade dessas instituições, o efetivo funcionamento do mecanismo de referência e contra referência de pacientes com as unidades demandantes e a facilidade de acesso dos pacientes.

Também se observa que há necessidade de um planejamento da gestão do SUS (PDR e PPI) que considere a demanda em saúde e que contemple as múltiplas demandas. ${ }^{11} \mathrm{Na}$ mesma linha, as propostas dirigidas ao estabelecimento de um pacto de responsabilidades entre vários municípios, que podem vir a compor, em conjunto, uma microrregião de saúde, implicam, em última análise, na criação de possibilidades de acesso a uma gama variada de ações e serviços que, de outro modo, não poderiam ser garantidos à população, principalmente aquela que habita os municípios menores, onde se constata mais insuficiências de infraestrutura do sistema.

Saúde (Santa Maria), v.38, n.2, p. 95-106, 2012. Lima, S. B. S.; Todendi, P. F.; Sarturi, F.; Pellenz, N. L. ISSN 2236-5843 
Segundo a nova proposta para regionalização da saúde (divisão otimizada do estado), o fluxo de pacientes tenderá a ser cada vez mais regionalizado, desafogando as principais cidades, economizando no transporte público desses pacientes e estimulando a economia local, já que em muitos casos os familiares costumam acompanhar os pacientes. ${ }^{12}$ Considerando que o tempo computacional para se obter a resposta ao fluxo de pacientes é muito pequeno (aproximadamente dois segundos), a ferramenta pode ser utilizada em uma futura e possivel integração computacional do sistema de saúde estadual para marcações de consultas e de internamentos hospitalares. Assim, os pacientes poderiam procurar 0 atendimento necessitado na Internet e obteriam a resposta rapidamente, facilitando a resolução de seu caso.

O princípio básico da regionalização é que a atenção à saúde deve ser oferecida, no máximo possível, pelo nível inferior do sistema. Para tal, é necessário equilibrar os desejos e necessidades do público de ter serviços de saúde perto de suas casas, assim como instalações centralizadas de maior prestígio e complexidade. A regionalização pressupõe a alocação de recursos de saúde em uma determinada área, em uma ordem que facilite 0 acesso, ofereça alta qualidade dos serviços, baixo custo, equidade, com uma melhor e mais rápida resposta aos desejos e necessidades dos consumidores.

O sistema integrado de transferência do paciente por sucessivos níveis de atenção está baseado na premissa de que os hospitais são instituições com cuidados especializados e que seus custos são substancialmente reduzidos através da implantação de outros serviços periféricos mais simplificados e resolutivos. A disponibilidade de ambulatórios e serviços domiciliares teria um efeito significativo não tanto sobre a taxa de hospitalização, mas sobre a permanência hospitalar. 0 enfoque de regionalização propõe-se a encontrar um equilíbrio entre a excessiva centralização estrutural e a descentralização total dos serviços de saúde. ${ }^{13}$

A NOAS 2001, o município pólo em geral deve prestar atenção básica nos diversos módulos assistenciais que a compõem, com atenção de média e alta complexidade, é o que deveria ser. ${ }^{6}$ Contudo, estes municípios que poderiam ser "polos", muitos ainda não estão prontos para prestar este tipo de serviço, e os pacientes acabam indo para centros maiores e mais afastados de suas cidades. A regionalização do Sistema Único de Saúde (SUS) ainda enfrenta importantes desafios, em particular a implantação do PDR, compondo assim municípios-polo de atenção. Com a regionalização dos serviços mais complexos, seria indiscutivelmente melhor a acessibilidade para os cidadãos e também suavizaria a demanda para os grandes centros que recebem diariamente, milhares de pacientes, vindos de todos os cantos do Estado.

\section{Conclusões}

Pode-se observar pelos resultados obtidos a escassa publicação no que se refere a estudos de regionalização dos serviços de saúde em municípios pólo, pois em 10 anos verificou-se a produção total de 10 artigos.

Também é perceptível que a criação de municípios-pólo não é objetivo de muitos

Saúde (Santa Maria), v.38, n.2, p. 95-106, 2012. Regionalização dos serviços de saúde - municíios polo: revisão bibliográfica de 2000-2010 ISSN 2236-5834 municípios, sendo a sua criação ainda de acordo com a demanda e as tecnologias que as regiões possuem. Assim, é necessário o desencadeamento e fortalecimento de ações políticas e técnico-administrativas no âmbito federal, estadual e municipal, tendo como eixo 0 fortalecimento do nível municipal e a organização dos sistemas microrregionais de saúde. 
Estes espaços podem introduzir mudanças gerenciais, organizativas e técnico-assistenciais que contribuem para a construção de modelos de atenção capazes de dar respostas adequadas aos problemas e necessidades de saúde da população de cada local.

Portanto, fazem-se necessários maiores estudos em relação à determinação de microrregiões em saúde; as capacidades de se tornar um município pólo, com população a ser atendida definida, distância a ser percorrida de cada município à cidade pólo, como deve ser feito seu financiamento e por fim promover uma integração entre os gestores de cada microrregião. Deste modo, realiza-se uma assistência integral e resolutiva à população assistida, organizando a gestão pública em saúde.

\section{Referências}

1. Brasil. Lei n. 8080 , de 19 de setembro de 1990. Dispõe sobre as condições para a promoção, proteção e recuperação da saúde, a organização e o funcionamento dos serviços correspondentes. Acesso em: 15/03/2011. Disponível em: <http://portal.saude.gov.br/portal/arquivos/pdf/lei8080.pdf >.

2. Carvalho, IA; Barbosa, RP. Políticas de Saúde: Fundamentos e Diretrizes do SUS. Florianópolis: Departamento de Ciências da Administração/UFSC; [Brasília]: CAPES: UAB, 2010. Bibliografia: Especialização em Gestão em Saúde, UFSM.

3. Souza, RR. O Sistema Público de Saúde Brasileiro. São Paulo, ago. 2002. Acesso em: 06/03/2011. Disponivel em: <http://www.opas.org.br/observatorio/arquivos/Sala299.pdf>.

4. Dourado, AD; Elias, MEP. Regionalização e dinâmica política do federalismo sanitário brasileiro. Revista de Saúde Pública vol. 45, São Paulo, fev. 2011. Acesso em: 15/03/2011. Disponível em: $<$ http://lilacs.bvsalud.org/?lang=pt>.

5. Teixeira, FC. Promoção e vigilância da saúde no contexto da regionalização da assistência à saúde no SUS. Caderno de Saúde Pública, vol. 18, Rio de Janeiro 2002. Acesso em: 15/01/2011. Disponível em: http://www.scielo.org/php/index.php>.

6. Brasil. NOAS-SUS 2001. Regionalização da Assistência à Saúde: Aprofundando a descentralização com equidade no acesso. Série A. Normas e Manuais Técnicos, n. 116. Brasília, 2001. Acesso em: 16/03/20011. Disponivel em: <http://datasus.gov.br>.

7. Viana, DLA. et al. Novas perspectivas para a regionalização da saúde. São Paulo em Perspectiva, v. 22, p.: 92-106, jan.jjun. 2008. Acesso em: 12/04/2011. Disponível em: <http://www.scielo.org/php/index.php>.

8. Brasil. CONASS (Conselho Nacional de Secretários de Saúde). Convergências e divergências sobre a gestão e regionalização do SUS. Brasília; CONASS, 2004. Acesso 18/05/2011. Disponivel em: $<$ <ttp://lilacs.bvsalud.org/?lang=pt>.

9. Bardin, L. Análise de Conteúdo. Lisboa. Editora 70. 281 p.

10. Machado, AJ. Pacto de gestão na saúde: até onde esperar uma "regionalização solidária e cooperativa"? Revista Brasileira de Ciências Sociais. Vol. 24, n. 71. São Paulo Out. 2009. Acesso em: 18/05/2011. Disponível em: <http://www.scielo.org/php/index.php>.

11. Stephan, AS. et al. Regionalização sob a ótica dos gestores: uma abordagem dialética. Revista APS, Minas Gerais 2010. Acesso em: 09/05/2011. Disponível em: <http://lilacs.bvsalud.org/?lang=pt>.

12. Scarpin, C. et al. Otimização no serviço de saúde no estado do Paraná: fluxo de pacientes e novas configurações hierárquicas. Gestão e Produção. Vol. 15, n. 2. São Carlos, Mai./Ago. 2008. Acesso em: 18/05/2011. Disponível em: <http://www.scielo.org/php/index.php>.

Saúde (Santa Maria), v38, n.2. p. 95-106, 2012 Lima, S. B. S.; Todendi, P. F.; Sarturi, F; Pellenz, N. L.

13. Artmann, E; Rivera, JUF. Regionalização em Saúde e mix público-privado. Julho, 2003. Acesso em issN 2236-5843 04/04/2011. Disponível em: 105 <http://www.ans.gov.br/portal/upload/biblioteca/TT_AS_05_EArtmann_RegionalizacaoEmSaude.pdf>. 


\section{Suzinara Beatriz Soares de Lima}

Endereço para correspondência - Av. Liberdade, 534 - Patronato - CEP 97020-490 - Santa Maria, RS.

E-mail: suzibslima@yahoo.com.br

Currículo Lattes: http://lattes.cnpq.br/6711164523602200

Recebido em 27 de setembro de 2012

Aprovado em 18 de outubro de 2012. 